\title{
Centrifugal Microfluidic Platform for Rapid, Multiplexed Detection of TB and HIV Biomarkers in Whole Blood Samples
}

\author{
Litvinov $\mathbf{J}^{1}$, Moen $\mathbf{S T}^{1,2}$, Berry $\mathbf{G J}^{3}$, Loeffelholz $\mathbf{M}^{3}$, Singh $\mathrm{AK}^{1,2}$ and Koh $\mathrm{CY}^{2}$ \\ ${ }^{1}$ Department of Microbiology and Immunology, University of Texas Medical Branch, Galveston, Texas, USA \\ ${ }^{2}$ Biotechnology and Bioengineering Department, Sandia National Laboratories, Livermore, California, USA
}

${ }^{3}$ Department of Pathology, University of Texas Medical Branch, Galveston, Texas, USA

"Corresponding author: Julia L, Department of Microbiology and Immunology, University of Texas Medical Branch, Galveston, Texas 77555, USA, Tel: 409-747-2484; E-mail: julitvin@utmb.edu

Received date: April 24, 2017; Accepted date: May 20, 2017; Published date: May 30, 2017

Copyright: (C) 2017 Julia L, et al. This is an open-access article distributed under the terms of the Creative Commons Attribution License, which permits unrestricted use, distribution and reproduction in any medium, provided the original author and source are credited.

\begin{abstract}
Infection with Mycobacterium Tuberculosis represents a significant threat to people with immune disorders, such as HIV-positive individuals, and can result in significant health complications or death if not diagnosed and treated early. We present a centrifugal microfluidic platform for multiplexed detection of tuberculosis and HIV biomarkers in human whole blood with minimal sample preparation and a sample-to-answer time of 30 minutes. This multiplexed assay was developed for the detection of two M.tuberculosis secreted proteins, whose secretion represents an active and ongoing infection, as well as detection of HIV p24 protein and human anti-p24 antibodies. The limit of detection for this multiplex assay is in the $\mathrm{pg} / \mathrm{mL}$ range for both HIV and M.tuberculosis proteins, making this assay potentially useful in the clinical diagnosis of both HIV and Tuberculosis proteins indicative of active infection. Antigen detection for the HIV assay sensitivity was $89 \%$, the specificity $85 \%$. Serological detection had $100 \%$ sensitivity and specificity for the limited sample pool. The centrifugal microfluidic platform presented here offers the potential for a portable, fast and inexpensive multiplexed diagnostic device that can be used in resource-limited settings for diagnosis of TB and HIV.
\end{abstract}

Keywords: Diagnostics; HIV; TB; Active infection; Multiplexed assay

\section{Introduction}

Tuberculosis (TB) is an infectious disease caused by aerobic bacteria of the Mycobacterium complex. It is spread through the air from lungs of infected persons during coughing or sneezing with the infectious dose being only a few bacteria. However, in many cases, the infection is latent and cannot be transmitted. In some cases, the infection becomes acute [1] and can be spread from person to person. One of the causes for latent $\mathrm{TB}$ to develop into acute $\mathrm{TB}$ is its combination with an impaired immune system, very often, a result of human immunodeficiency virus (HIV) infection [2]. Infection with HIV leads to an increased risk of developing, re-appearing, or having a reinfection with TB shortly after the onset of HIV infection, with risks increasing, as a patient becomes increasingly immunodeficient $[3,4]$. The two diseases accelerate each other to form a lethal outcome [5]. Currently, it is estimated that as much as one-third of world's population that is infected with HIV is also co-infected with TB [6]. Infection with $\mathrm{TB}$ is the leading cause of mortality among HIVinfected patients. According to World Health Organization, 25\% of fatalities among people infected with HIV are due to the TB disease [7]. The CDC has reported that infection with HIV is the major factor for transforming latent TB infection into an active disease [8].

The co-infection poses a great challenge to the diagnosis and treatment of both diseases. For example, during early HIV infection stage, there is a noticeable decrease in production of CD4+ cells, which also leads to an increased risk of latent TB infection to advance to active $[9,10]$. The active TB, in its turn, infects alveolar macrophages and limits the ability of the body's defense system to effectively contain its growth. The co-infection increases the viral and bacterial replication [11]. The increase of viral load on macrophages and other immune cells co-infected with both HIV and TB results in acute TB due to the existing HIV infection, increasing the morbidity and the mortality of the infected patients $[12,13]$.

Currently available diagnostic assays can detect either HIV or TB with high sensitivity and specificity, but in order to differentiate between latent and active stages of TB, strategically different assays need to be developed. The existing diagnostic assays are based on host immune response and have to be performed and analyzed simultaneously $[14,15]$. The TB skin or IGRA test do not differentiate between latent and active infections [16-18]. In addition, the IGRA test is not accurate in people infected with HIV since the test checks for Tcell secreted proteins (IFN-g) that are decreased during the ongoing HIV infection [19-21]. Among the many HIV detection tests available are the ELISA for detection of HIV antibodies as soon as 2 to 12 weeks after onset of infection and the detection of p24 antigen in blood 3 to 28 days. The two rapid tests available are for the HIV antibody detection in whole blood or saliva. Unlike the ELISA and rapid tests, the nucleic acids amplification tests (NAAT) detect genetic material (RNA) of the virus instead of antibodies. Liu et al showed a detection of TB secreted proteins using NanoDisk-MS in both HIV-positive and HIV-negative population with high specificity and selectivity [22]. However, the assay required long sample preparation time. Until recently, according to McNerney and Daley [23], there were no tests that can compare to sputum smear microscopy and, in addition to long analysis time of each smear, such tests required a microscopy abilities and a skilled technician. However, many advances in analytical techniques were made and the Cepheid GeneXpert MTB test now allows detection of M.tuberculosis directly from sputum sample within 
3-4 hours. It was approved by FDA and is claimed to be more sensitive than smear analysis [24,25]. An already established PCR detection of M.tuberculosis, though rather expensive, is very sensitive, requires about two hours to complete, and is being used in remote locations in resource-limited settings [24]. An alternative approach to TB detection in HIV-positive individuals could be detection of secreted bacterial proteins, which will indicate actively reproducing bacteria. The detection of elevated numbers of secreted proteins or toxins would be the direct indication of an active infection. This strategy bypasses the problem of depending on the host immune response (which is likely not working properly in active HIV infection) to make a diagnosis of infection. Ag85B and $38-\mathrm{kDa}$ represent such proteins in tuberculosis infection [26]. Both proteins impair host immunity by inactivating CD4 and CD8 T-cells. Ag85 complex is responsible for adherence and dissemination of TB inside the host as well as for cell wall synthesis [27]. The $38-\mathrm{kDa}$ protein is a phosphate binding protein that serves as an initial receptor for active transport $[28,29]$. The ag85 complex accounts for $30 \%$ of the total secreted proteins of TB and the $38-\mathrm{kDa}$ protein accounts for another $10 \%$. In addition, the ag85 complex can be detected in HIV-positive patients with high specificity [30-32]. The detection of bacterial and viral proteins is more reliable compared to the detection of antibodies and can be directly correlated to the number of reproducing bacteria and viruses [23]. For example, a single HIV virus has 2,000 copies of $\mathrm{p} 24$ protein (or, $1 \mathrm{pg}$ of $\mathrm{p} 24$ corresponds to $10,000 \mathrm{HIV}$ virus particles) [33]. Thus, the quantitative detection of p24 protein and viral load can result in placement of patient on the timeline of the initial HIV infection in order to achieve a better understanding of the onset time of TB.

In non-infected patients, no HIV or TB proteins should be detected. The main idea behind this assay is the detection of bacterial secreted proteins, which human body cannot produce. However, it is impossible to predict the concentration range of secreted proteins in infected patients, as every bacteria has its own requirements for reproduction and every human body reacts differently to bacterial intervention.

In this paper, we show the development of an ELISA-like multiplexed centrifugal sedimentation assay for detection of Mycobacterium Tuberculosis secreted proteins and HIV p24 protein along with antibodies in human whole blood. The assay was validated in samples spiked with protein of interest in presence of HIV-related protein and antibodies. For the proof of concept, the assay was also validated in clinical serum samples. The assay has a limit of detection lower than the regular ELISA, while having an advantage of detecting multiple proteins and antibodies from one blood sample within 30 minutes.

\section{Materials and Methods}

\section{Microfluidic assay design}

The basic principle of the centrifugal microfluidic assay is that centrifugal force propels the liquid from the center of the disk towards the rim of the disk during spinning. This centrifugal movement requires only a simple motor to rotate the disk and to move the fluid in one direction. The entire assay is performed on a single disk without the need of centrifuges, external pumps, or any other additional equipment. The fluid movement inside the microfluidic disk does not depend on ionic strength or $\mathrm{pH}$ of solution. The reagents movement inside the disk' wells depends only on the principle that heavier particles will move further through the gradient than lighter particles, depending on the density and viscosity of the density gradient [34].
The heaviest particles, in our case, the carboxylated silica beads with analyte, capture and detection antibodies will move through the density gradient all the way to the tip of the well at the rim of the disk. The unreacted reagents, as excess analyte and detection antibodies will be left behind the density gradient since their density is less than the density of the gradient. This approach of moving reagents through the gradient allows adding all assay components to the disk simultaneously and performing an assay without the washes between different steps. The density gradient acts like a wash, removing the non-specific binding and eliminating false-positives. The sample, being pushed through the gradient, experiences friction forces, helping it to eliminate the non-specific attachments and retain only the covalently bonded and specific ones.

The centrifugal microfluidics approach becomes very useful especially when working with whole blood samples [35]. One of the biggest pros is that absolutely no sample preparation or cleanup is necessary. Whole blood can be pipetted to the disk as is, without prior separation steps, which are done directly on the disk while the disk is spinning. When a $10 \mu \mathrm{L}$ whole blood sample after a 20 -minute incubation with analyte of interest, capture beads and detection antibodies is pipetted onto a disk, the only remaining step is to turn the motor on and spin the disk. The reagents will separate according to their density. The beads with capture antibody, bound analyte and detection antibody, still being the heaviest particles, will spin all the way through the density gradient to the tip of the well, leaving behind the unreacted reagents and the rest of the blood sample separated into fractions. The red blood cells will be right at the top of density gradient, followed by the white blood cells closer to the center of the disk, followed by other fluids leftovers from density gradient, beads and detection antibody, closest to the center of the disk.

\section{Statistical analysis}

The average background fluorescence signal ( $n=3$, mean intensity of silica beads with capture antibody only, without analyte and detection antibody) was subtracted from the collected individual raw data points. The average value of the signal intensity for every protein or antibody concentration was calculated. To normalize the data, all the averaged values were divided by the averaged fluorescence intensity of the highest protein or antibody concentration. The standard deviation was determined by calculating the square root of the sum of squared standard deviations of background and averaged data points. The error bars represent \pm 1 standard deviation. Kaleidagraph software was used for curve fitting and determining of limit of detection (LOD), limit of quantification (LOQ), R2 and chi-squared values. $0.1 \%$ error and firstdegree parameter partial derivatives were allowed for calculations purposes. All curves are represented as sigmoidal fit with $\mathrm{R} 2$ values are higher than 0.98 . The limit of detection and the limit of quantification were set as three and ten standard deviations, respectively, higher than the signal for negative control sample, which included functionalized silica beads incubated with corresponding fluorescently labeled antibody but without the analyte of interest.

\section{Silica beads functionalization}

$20 \mathrm{mg}$ of $1 \mathrm{~mm}$ carboxylated silica beads were washed with $1000 \mathrm{~mL}$ of $0.1 \mathrm{M}$ MES buffer twice, sonicated $20 \mathrm{~min}$, washed twice with MES, and resuspended in $800 \mathrm{~mL}$ MES. Ten milligram each of EDC and NHS were dissolved in $200 \mathrm{~mL}$ MES, added to the washed silica beads and allowed to incubate for $30 \mathrm{~min}$ at $25^{\circ} \mathrm{C}$ with continuous rotation. The beads were washed twice with $1 \mathrm{~mL}$ MES, twice with $1 \mathrm{~mL}$ PBS, 
and resuspended in $900 \mathrm{~mL}$ PBS. One hundred microliters $\mathrm{NaHCO}_{3}$, and $20 \mathrm{mg}$ of desalted antibody were added to reaction and allowed to incubate overnight at $4^{\circ} \mathrm{C}$ with continuous rotation. After two washes with PBS, the beads were blocked with $3 \%$ SeaBlock at $25^{\circ} \mathrm{C}$ with continuous rotation for $60 \mathrm{~min}$, washed with wash buffer and resuspended in $100 \mathrm{~mL}$ wash buffer. The beads can be stored in wash buffer at $4^{\circ} \mathrm{C}$ up to six months.

Proteins and antibodies: M.tuberculosis ag85B full-length protein (ab83471), rabbit polyclonal anti-ag85B antibody (ab43019) and M.tuberculosis $38 \mathrm{kDa}$ full length protein (ab119461) were purchased from Abcam Inc. (Cambridge, MA). Anti-38 kDa protein monoclonal antibodies (NB100-73190, clone HTM81 and NB100-73191, clone HTM82) were purchased from Novus Biologicals USA (Littelton, CO). Anti-HIV p24 antibodies (ab9071 and ab9072) were purchased from Abcam Inc. (Cambridge, MA). Human polyclonal anti-p24 antibody (cat \# 2503, IgG fraction purified from HIV-1 immune human serum) and recombinant HIV gag p24 protein (cat \# 1003) were purchased from ImmunoDX (Woburn, MA). Mouse anti-human IgG antibody (FC-AF488) was purchased from SouthernBiotech (Birminghan, AL).

Microspheres: Alexa 488 Fluorescent Microspheres (T-8864), Alexa 647 Fluorescent Microspheres (A-20186) were obtained from Invitrogen (Eugene, OR). Carboxylic acid functionalized silica microspheres were obtained from Bangs Laboratories, Inc (SC06N/ 11491; Fishers, IN).

Wash buffer: SeaBlock $(1 \% \mathrm{v} / \mathrm{v}), 5 \mathrm{mg} \mathrm{NaN3}(0.05 \% \mathrm{w} / \mathrm{v}), 5 \mathrm{~mL}$ Tween $20(0.05 \% \mathrm{v} / \mathrm{v})$ in $10 \mathrm{~mL}$ PBS. Other buffers used were PBS (138 $\mathrm{mM} \mathrm{NaCl}, 2.7 \mathrm{mM} \mathrm{KCl}, 10 \mathrm{mM} \mathrm{Na}_{2} \mathrm{HPO}_{4}, 1.8 \mathrm{mM} \mathrm{KH}_{2} \mathrm{PO}_{4}$ ), MES $(0.1 \mathrm{M})$, and sodium bicarbonate $(1 \mathrm{M})$.

Density media: Histopaque 1119, Sigma Aldrich (11191-100 mL).

Dissociation buffer for clinical samples: $1 \mathrm{M} \mathrm{HCl}, 1 \mathrm{M} \mathrm{NaOH} / 0.5 \mathrm{M}$ HEPES. In order to separate the bacterial and viral proteins from the human antibodies in serum samples, $1 \mathrm{M}$ solution of $\mathrm{HCl}$ was incubated in 1:1 volume with each sample for 20 minutes at room temperature. The sample was quenched with 1:1 volume of $1 \mathrm{M}$ $\mathrm{NaOH} / 0.5 \mathrm{M}$ HEPES buffer and allowed to stabilize for 5 minutes.

\section{Antibody labeling with fluorophore}

Using $100-\mathrm{kDa}$ filter, the antibody was concentrated to $10 \mathrm{mg} / \mathrm{mL}$. Fourty five microliters PBS and $5 \mathrm{~mL} \mathrm{NaHCO} 3(0.1 \mathrm{M})$ were added to concentrated antibody. Five microliters of stock Alexa 488 Fluorescent microspheres $(9.51 \mathrm{E}+12$ spheres $/ \mathrm{mL})$ were mixed with $5 \mathrm{~mL}$ DMSO; $10 \mathrm{~mL}$ of mix were added to detection antibody solution and incubated for two hours at $25^{\circ} \mathrm{C}$ with continuous rotation. The reaction was eluted with Zeba $7 \mathrm{kDa}$ column based on manufacturer's protocol and the eluent was measured at A280 and A488 to determine the degree of labeling. The concentrated fluorophore-labeled antibody could be stored in $1 \% \mathrm{v} / \mathrm{v}$ SeaBlock/PBS solution at $4^{\circ} \mathrm{C}$ up to six month; antibody diluted to a working concentration has to be prepared daily.

\section{Microfluidic disk set-up}

The disks were designed in AutoCAD and fabricated from three layers: a layer of pressure-sensitive double-sided adhesive (9474- $12 \times$ 12, 9474LE 300 LSE, 3M, St. Paul, MN) sandwiched between two plastic sheets (cast acrylic PD-15401710, $0.060 \times 12 \times 24$, McMaster Carr, Atlanta, GA). The top plastic layer contained fluid access and vent openings, while the channels were cut in the adhesive layer. The bottom layer of the disk contains no openings. Universal Laser Systems
60 Watt VLS 6.60 was used to draw the pattern in layers. The disks were manually assembled and the layers were pressed together using Jack Richeson \& Co. "Baby Press" (Kimberly, WI). The total final volume of each of the 21 wells on the disk was $15 \mathrm{~mL}$.

\section{Fluorescence detection}

Fluorescent detection of labeled antibodies in the disk was performed using a Nikon Inverted Microscope Eclipse Ti, Melville, NY. The microscope lens with magnification 10x and exposure time of 40 milliseconds were used throughout all experiments. The excitation and emission wavelengths were 495 and $519 \mathrm{~nm}$, respectively. An area of $1,000,000$ pixels $\left(0.5 \mathrm{~mm}^{2}\right.$, approximately the entire bead area) was designated as "detection area" to record the mean intensity of each sample. The mean intensities of three replicas of each sample were collected and averaged to determine the average values and standard deviation of samples.

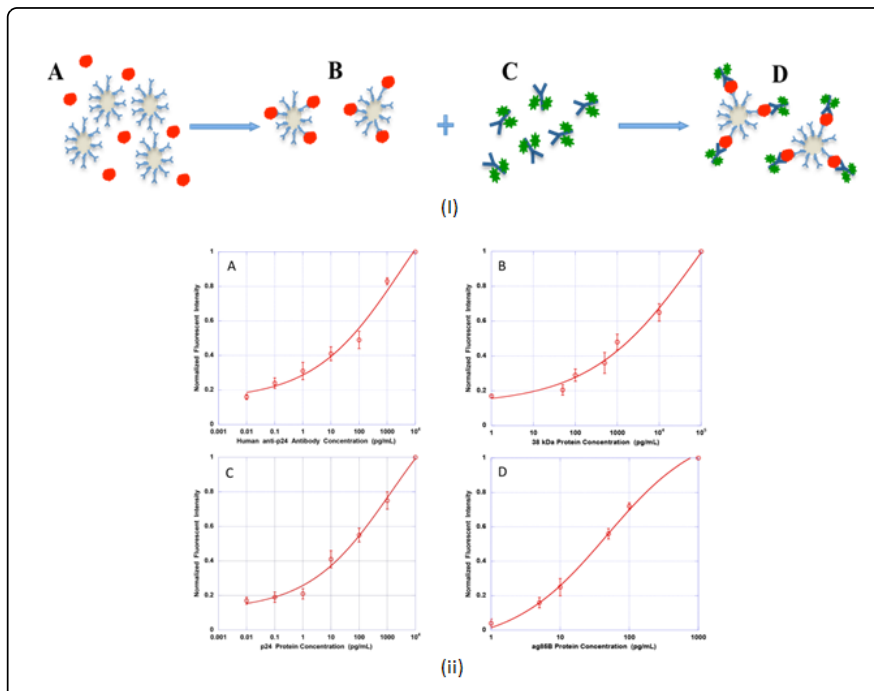

Figure 1: (i) Analyte of interest in serial dilutions is added to the beads with capture antibody (A). The reaction is allowed to proceed for 12 minutes (B). Then, the detection antibody (C) is added for 10 minutes. The detection antibodies bind to analyte of interest (D). The disk is spun, forcing the beads with attached analyte and detection antibody to pass through the density gradient, while unreacted analyte and detection antibody are trapped inside the density gradient away from the beads. The fluorescent signal from the detection antibody attached to beads through analyte is quantified by fluorescent microscopy. (ii) Supplementary Figure 1: Detection of single proteins and antibodies. The analyte of interest HIV anti-p24 antibody (A), TB 38kDa protein (B), HIV p24 protein (C), and TB ag85B protein (D) was spiked into human whole blood and reacted with its corresponding capture particles for 12 minutes. After incubation with corresponding detection antibody for 10 minutes, the reaction was added to the disk with density gradient and spun at 5000 RPM to allow separation of capture beads with bound analyte and detection antibody from unbound reactants. Fluorescence signal was detected and quantified at the bead area at the tip of the channel.

Mean intensity of almost the entire tip area, $0.5 \mathrm{~mm}^{2}$ that was designated as reading area, was recorded for all samples. The images were acquired at room temperature. The raw data was then averaged, 
subtracted background, and normalized. No significant photobleaching was observed throughout our experiments due to relatively photostable dye (Alexa 488), short exposure time (40 milliseconds), large working distance $(7.5 \mathrm{~mm})$, and illumination of samples through 10x (low-power) objective. The exposure of samples to the light was minimized to 1-2 seconds during focusing. Standard excitation intensity, as well as standard gain and power were used in all experiments.

\section{Assay design}

Silica beads functionalized with capture antibody were incubated with protein of interest in ten-fold serial dilutions in human whole blood for 12 minutes. Detection antibody labeled with Alexa488 fluorophore was added to each reaction at a concentration $60 \mathrm{nM}$ and allowed to incubate for additional 10 minutes, as shown in Figure 1. Density gradient Histopaque 1119, $3 \mathrm{~mL}$, was applied to each well and briefly spun. After incubation was done, $5 \mathrm{~mL}$ of reaction volume (in 3 replicas) were dispensed into wells on a disk and the disk was spun at $5000 \mathrm{rpm}$ for $45 \mathrm{sec}$. A more detailed assay design is explained elsewhere [36].

\section{Results and Discussion}

To gain an insight on how TB is progressing in a specific patient, one can evaluate the type of secreted proteins as well as their amounts. For example, ag85 complex appears as the first sign of an active TB, while appearance of $38-\mathrm{kDa}$ protein indicates advanced or established disease $[37,38]$. Also, the ag85 complex can be detected in culture media as early as 2-4 days, much earlier than the antibodies at detectable levels start being produced. Keeping in mind that the survival of patients with advanced HIV infection and onset of active TB may only be measured in days or weeks, the earliest possible detection of acute TB is crucial $[39,40]$.

The preliminary experiments were performed in different batches of single donor human whole blood (cat \# IPLA-WB1, Innovative Research, Novi, MI). All blood was tested and found negative or nonreactive by Innovative Research Inc. using FDA approved methods. Upon receipt, the blood was aliquoted into $1 \mathrm{~mL}$ volumes and stored at $4^{\circ} \mathrm{C}$. Before each experiment it was allowed to normalize to room temperature for 30 minutes. All blood had $10 \%$ sodium citrate as anticoagulant.

\section{Detection of HIV and TB markers in spiked donor blood}

In all assays, the background fluorescence was subtracted from the fluorescence signal and the detection limit was calculated as three standard deviations from the negative control sample.

\section{Single protein detection}

Protein of interest was spiked into blood in 10-fold dilution series. For detection of $38-\mathrm{kDa}$ protein, antibody clone HTM82 was used for capture and antibody clone HTM81 was used for detection. For detection of ag85B protein, the same polyclonal anti-ag85B antibody was used for capture and detection. For detection of HIV p24 protein, purified human polyclonal anti-p24 antibody was used for capture and antibody clone 9072 was used for detection. For the detection of human polyclonal anti-p24 HIV antibodies, human p24 protein was used as capture and mouse anti-human $(\mathrm{Fc})$ antibodies were used for detection. All proteins were ten-fold serially diluted starting at the concentration $1 \mathrm{ng} / \mathrm{mL}$ and purified polyclonal human anti-p24 antibody was diluted three-fold starting at the concentration of $6.7 \mathrm{nM}$ $\left(4 \times 10^{8}\right.$ antibodies $\left./ \mathrm{mL}\right)$. The procedure is described in Assay Design section.

\section{Multiplexed protein detection}

All experiments were performed on the same day in the same batches of blood as the single protein detection. For every analyte of interest, a mix of other analytes was added each at a concentration 1 $\mathrm{ng} / \mathrm{mL}$ per reaction. For example, for the multiplexed detection of ag85B protein, the human anti-p24 antibody, $38 \mathrm{kDa}$ and p24 proteins were added to each sample including the negative control. The assays were performed as explained in "Assay Design" section and the results were analyzed with fluorescent microscope.

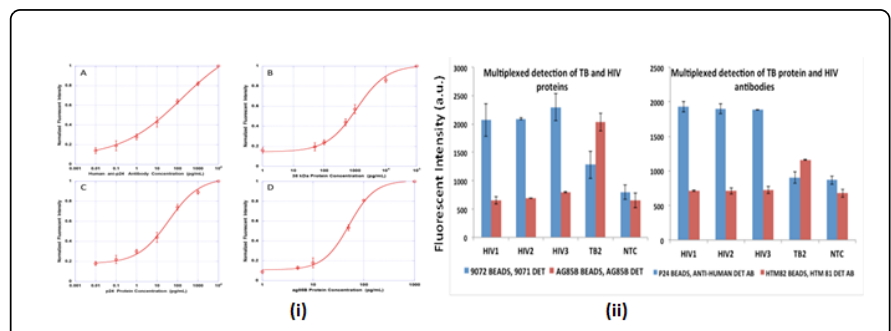

Figure 2: (i) Multiplexed detection of human HIV anti-p24 antibody (A), TB 38kDa protein (B), HIV p24 protein (C), and TB ag85B protein (D). The analyte of interest was spiked into human whole blood and reacted with its corresponding capture particles for 12 minutes. After incubation with corresponding detection antibody for 10 minutes, the reaction was added to the disk with density gradient and spun at 5000 RPM to allow separation of capture beads with bound analyte and detection antibody from unbound reactants. Fluorescence signal was detected and quantified at the bead area at the tip of the channel. (ii) Supplemental Figure 2.

In Figure 2, the assay Limit of Detection and Limit of Quantification are as following: $3.12 \mathrm{pg} / \mathrm{mL}$ and $12.95 \mathrm{pg} / \mathrm{mL}$ respectively for the single p24 detection, $6.93 \mathrm{pg} / \mathrm{mL}$ and $23.07 \mathrm{pg} / \mathrm{mL}$ for multiplexed p24 detection; $24.56 \mathrm{pg} / \mathrm{mL}$ and $146.91 \mathrm{pg} / \mathrm{mL}$ for single $38 \mathrm{kDa}$ protein detection, $53.32 \mathrm{pg} / \mathrm{mL}$ and $168.16 \mathrm{pg} / \mathrm{mL}$ for multiplexed $38 \mathrm{kDa}$ protein detection; $3.11 \mathrm{pg} / \mathrm{mL}$ and $10.25 \mathrm{pg} / \mathrm{mL}$ for single ag85B protein detection, $7.53 \mathrm{pg} / \mathrm{mL}$ and $18.76 \mathrm{pg} / \mathrm{mL}$ for multiplexed ag85B protein detection; $1.76 \mathrm{pg} / \mathrm{mL}$ and $151 \mathrm{pg} / \mathrm{mL}$ for single human antip24 antibody, $135.5 \mathrm{pg} / \mathrm{mL}$ and $1.2 \mathrm{ng} / \mathrm{mL}$ for multiplexed human antip24 antibody. The data for single protein/antibody detection is located in Supplementary Figure 2.

\section{Detection of HIV and TB markers in patient samples}

Frozen de-identified serum samples previously confirmed to be HIV-positive by ELISA and Western Blot followed by PCR for viral load $(n=18)$ were tested. In addition, HIV-positive serum from one active pulmonary TB-positive case and serum from one TB-positive, HIV-negative case ( $n=2$, confirmation of TB by PCR from sputum) were tested. Each sample was analyzed for presence of human anti$\mathrm{HIV}$ antibodies, p24 protein, bacterial 38kDa protein, bacterial ag85B protein, human anti-38kDa antibody, and human anti-ag85B antibody using the same reagents as in spiked samples ("Assay Design" section). 
Each sample was treated with buffer to separate the antibodies from proteins as described in Materials and Methods section. The sample then was serially diluted 10 -fold with wash buffer and the assay was performed as described in "Single Protein Detection". The negative control samples represented samples that were HIV-negative as confirmed by PCR and TB-negative based on clinical picture. The negative control for the NTC samples (No Template Control samples) were the assays run in buffer, as an opposite to assays run in blood sample. The specificity of the assay for HIV detection was 7/8 (87.5\%) and the sensitivity was $18 / 20(90 \%)$.

Between the two available patient samples with TB infection, one had the co-infection with HIV. When analyzing for HIV and TB proteins, the sample dilutions corresponded to the dose-response curve (Figure 3 ) and the patient samples were confirmed to be HIV and $\mathrm{TB}$ positive.

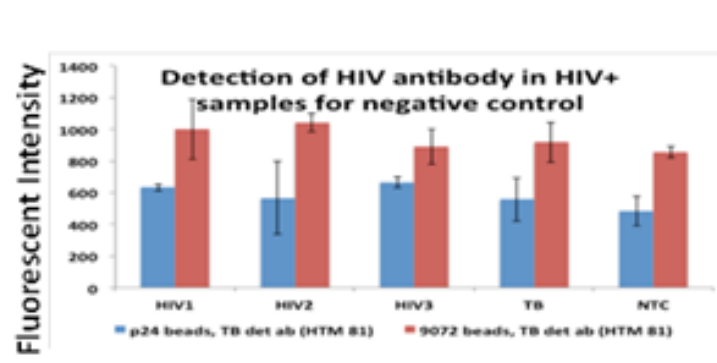

(i)

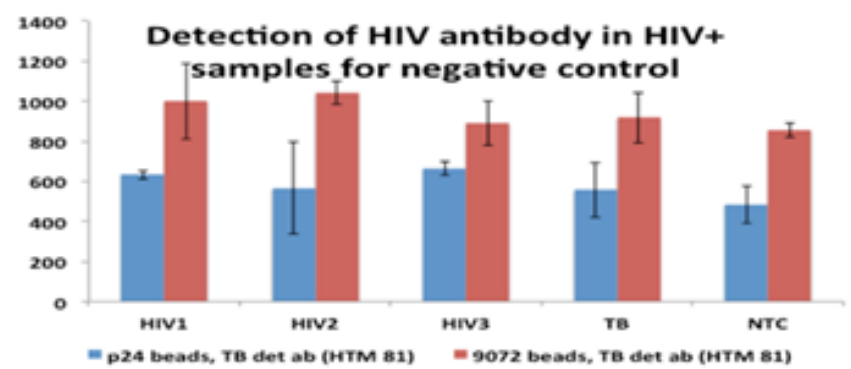

(ii)

Figure 3: (i) Detection of proteins in sample with TB/HIV co-infection. The HIV/TB co-infection sample was treated with $\mathrm{HCl} / \mathrm{NaOH}-\mathrm{HEPES}$ buffers and serially diluted with wash buffer. Capture beads modified with capture antibodies and the corresponding detection antibodies were incubated with samples. 9072 antibody beads (blue) capture p24 protein from sample, 9071 antibody serves as detection. Anti-ag85B antibody beads (red) capture ag85B protein; the same anti-ag85 antibody serves as detection. HTM82 antibody (anti-38kDa) beads (green) capture $38 \mathrm{kDa}$ protein; HTM81 (anti-38kDa) serves as detection antibody. (ii) Supplemental Figure 3.

The second TB-positive sample was HIV-negative (confirmed by PCR) and showed fluorescent signal similar to the background signal in assays for HIV detection. The assay for TB protein detection showed a dose-response result (Figure 4).

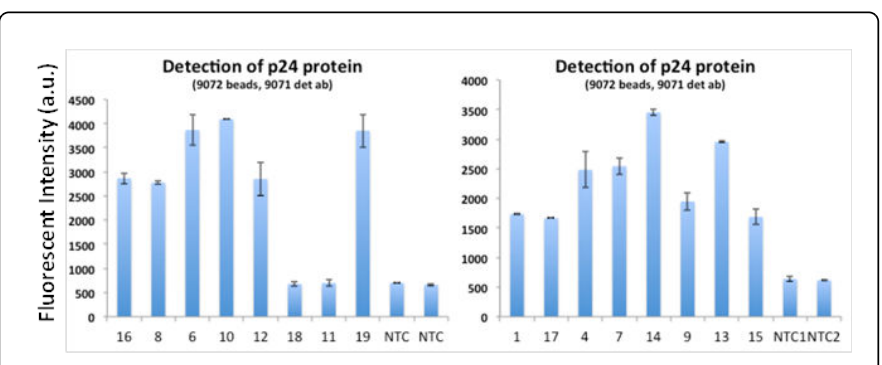

Figure 4: Detection of TB proteins in TB-positive/HIV-negative sample. Tuberculosis sample was treated with $1 \mathrm{M} \mathrm{HCl}$ for 15 minutes and $1 \mathrm{M} \mathrm{NaOH} / \mathrm{HEPES}$ for 5 minutes. The treated sample was serially diluted 10 -fold. 10 microliters of sample dilutions were incubated with anti-ag85B antibody beads and another 10 microliters were incubated with anti-38kDa (HTM 82) beads for 10 minutes. 5 microliters of detection antibody (anti-ag85B and HTM 81 ) were added and allowed to incubate for 10 minutes. The "zero" sample was the TB-negative/HIV-negative sample diluted 1:10.

In order to simultaneously detect HIV and TB proteins, negative control experiments were performed to evaluate cross-reactivity of human/commercial antibodies. Three different HIV-positive samples and one TB-positive sample were treated for protein separation and incubated in non-specific assay. Each sample was incubated with HIV and TB reagents, such that three HIV samples should be only HIV- positive and the TB sample should only be TB-positive (sample TB2 was the TB-positive, HIV-negative sample). None of the HIV samples showed any cross-reactivity with TB reagents, however, the TB sample showed an elevated background when incubated with 9072 HIV capture antibody (Supplementary Figure 2).

SF2: Specific and non-specific binding assays for protein and antibody detection in HIV and TB samples. Three HIV-positive/TB negative and one TB-positive/HIV-negative samples were treated with $\mathrm{HCl} / \mathrm{NaOH}$-HEPES buffers and diluted 1:1000 with wash buffer. All the samples were incubated with HIV beads (blue) and TB beads (red). When the TB sample was incubated with HIV 9072 ab beads and 9071 det ab, it showed an elevated signal, compared to the NTC control, but not after incubation with $\mathrm{p} 24$ protein beads and anti-human det ab. The HIV-samples did not show cross-reactivity with TB beads and antibodies.

The negative control experiments were conducted on the HIVpositive samples to confirm the antibody cross-reactivity seen in the SF2. HIV capture beads modified with p24 protein and HIV 9072 antibodies were incubated with HIV-positive samples and added an HTM81 TB detection antibody in both cases. As shown on the graph, the elevated background independent of dose-response curve existed when 9072 HIV capture beads were incubated with HTM 81 TB detection antibodies. This experiment confirmed the cross-reactivity seen in SF3.

SF3: Cross-reactivity assays for multiplexed assay tests. Negative control assay was performed on HIV-positive samples. The nonspecific TB detection antibodies were added to incubate with HIVpositive samples and HIV capture beads to bind either p24 protein (9072 antibody beads) or human anti-p24 antibodies (p24 protein beads) from the samples. As can be seen, the 9072 capture beads cross- 
react with the $\mathrm{TB}$ detection antibodies, contributing to a higher background signal. The p24 protein beads do not cross-react with TB det ab.

Among the 19 available HIV-positive samples, one of the samples had lysed red blood cells and could not be analyzed. The remaining 18 HIV-positive samples were treated with $\mathrm{HCl}-\mathrm{NaOH} / \mathrm{HEPES}$ buffer and analyzed for presence of antibodies and proteins. As shown, the assays for protein detection could not detect p24 protein in two of the samples (samples 11 and 18), as shown in SF3. The possible explanation is that a) the infection is established and is older that 3-5 months, so the antibodies have higher avidity and do not release the protein even after the buffer treatment, and b) the patients undergo an HIV treatment and do not have the detectable amount of the virus any longer. The antibody detection, on the other hand, did not show any false-negatives for any of the samples (SF4). The negative control for both protein and antibody assays were the HIV-negative samples.

SF4: Detection of p24 protein in HIV-positive samples. HIV samples were treated with $1 \mathrm{M} \mathrm{HCl}$ for 15 minutes and $1 \mathrm{M} \mathrm{NaOH} / \mathrm{HEPES}$ for 5 minutes. The treated samples were diluted 1:1000. 10 microliters of sample dilution were incubated with anti-HIV antibody beads for 10 minutes. 5 microliters of HIV detection antibody were added and allowed to incubate for 10 minutes. The "NTC" samples were the HIVnegative sample diluted 1:1000. Out of 19 HIV-positive samples, p24 protein was detected in 16 samples. One of the samples had red blood cells lysed and was not used. Two samples (18 and 11) showed a falsenegative signal for $\mathrm{p} 24$ protein detection.

SF5: Detection of human anti-p24 antibodies in HIV-positive samples. HIV samples were treated with $1 \mathrm{M} \mathrm{HCl}$ for 15 minutes and 1 $\mathrm{M} \mathrm{NaOH} / \mathrm{HEPES}$ for 5 minutes to separate the protein-antibody complexes. The treated samples were diluted 1:1000. 10 microliters of sample dilution were incubated with HIV p24 protein beads for 10 minutes. 5 microliters of HIV anti-human detection antibody were added and allowed to incubate for 10 minutes. The "NTC" samples were the HIV-negative sample diluted 1:1000. Out of 19 HIV-positive samples, human anti-p24 antibody was detected in all 19 available samples. The two samples (18 and 11) that showed a negative signal for p24 protein detection, showed a positive result for antibody detection.

To further characterize the ability to produce reliable result, the assay was performed on samples previously determined HIV-negative by PCR. Among 7 samples, one showed a slight increase in fluorescence signal (1400 a.u. compared to 600 a.u of the background or to 3500 a.u. average signal of positive control). The negative control for the NTC samples were the assays performed in buffer. The detection of human anti-p24 antibodies in negative control samples gave negative results. There were no false-positives. The negative control for NTC samples were wash buffer samples for both protein and antibody detection assays. The capture beads for antibody assay detection had p24 protein beads and the detection antibody was antihuman (SF6).

SF6: Detection assay in HIV-negative samples. HIV-negative samples were treated with $1 \mathrm{M} \mathrm{HCl}$ for 15 minutes and $1 \mathrm{M} \mathrm{NaOH} /$ HEPES for 5 minutes in order to have comparable time and dilution scales. The treated samples were diluted 1:1000. 10 microliters of sample dilution were incubated with HIV anti-p24 antibody beads for 10 minutes. 5 microliters of HIV anti-human detection antibody were added and allowed to incubate for 10 minutes. Out of seven available HIV-negative samples, one samples showed a slightly elevated positive result for p24 protein. However, no anti-p24 antibodies were detected later for that sample (results not shown).

\section{Conclusion}

The primary goal of this work was to develop a proof-of-concept multiplexed assay for detection of M.tuberculosis secreted proteins in HIV-positive patients in limited settings environment. The detection of secreted proteins is the most reliable way of diagnostic of acute ongoing disease, as an opposite of antibody detection, which can be present also during latent infection. As shown, our microfluidic immunoassay is a fast ( 30 minutes) and simple way to detect the secreted proteins at very low levels $(\mathrm{pg} / \mathrm{mL})$ directly from human blood samples without long time of sample preparation. In a spiked multiplexed assay, the limit of detection for p24 protein was 6.93 $\mathrm{pg} / \mathrm{mL}$, human anti-p24 antibody $5.62 \mathrm{e} 6 \mathrm{ab} / \mathrm{mL}$, ag85B protein 7.53 $\mathrm{pg} / \mathrm{mL}$, and $38-\mathrm{kDa}$ protein $53.32 \mathrm{pg} / \mathrm{mL}$.

To confirm the spiked assays, clinical samples with known infection status (determined by PCR) were analyzed to detect HIV and TB. The two available TB samples were confirmed to have the secreted TB proteins and human antibodies by our assay. Among the $18 \mathrm{HIV}$ positive samples, only 16 samples were confirmed to have the p24 protein present (2 were false-negative) and all 18 samples were confirmed to have the human anti-p24 antibodies. Among the seven available HIV-negative samples, one was HIV false positive in p24 protein detection. None of the negative samples were positive for antip24 antibody detection.

This work was a proof of concept that active tuberculosis disease can potentially be detected based on bacterial secreted proteins from blood samples. Furthermore, the assay can be used for detection of other proteins of interest by substituting the capture and detection antibodies and can be developed within a short period of time.

\section{Declarations}

\section{Ethics approval}

This research was approved by the University of Texas Medical Branch Institutional Review Board with a waiver for consent, protocol identification number 08-182.

\section{Availability of data and materials}

The datasets used and/or analysed during the current study are available from the corresponding author on reasonable request.

\section{Competing Interests}

The authors declare that they have no competing interests.

\section{Funding}

This research is funded by NIH-NIAID grant number R01AI098853. The funding agency had no role in the design of the study and collection, analysis, and interpretation of data and in writing the manuscript.

\section{Author's Contributions}

All authors made critical contributions to the conception and design of the study. JL and GB performed experiments with patient samples. 
JL developed assays and was the major contributor in writing the manuscript. All authors read, revised, and approved the final manuscript.

\section{Acknowledgements}

Sandia National Laboratories is a multi-program laboratory managed and operated by Sandia Corporation, a wholly owned subsidiary of Lockheed Martin Corporation, for the U.S. Department of Energy's National Nuclear Security Administration under contract DE-AC04-94AL85000. SAND2015-1581 J.

\section{References}

1. Aaron L, Saadoun D, Calatroni I, Launay O, Mémain N, et al. (2004) Tuberculosis in HIV-infected patients: a comprehensive review. Clin Microbiol Infect 10: 388-398.

2. Li W-G, Zhao L, Zhao H (2015) Epidemiology of HIV-associated tuberculosis in Urumqi, China. Transplant Proc 47: 2456-2459.

3. Wood R, Maartens G, Lombard CJ (2000) Risk factors for developing tuberculosis in HIV-1-infected adults from communities with a low or very high incidence of tuberculosis. J Acquir Immune Defic Syndr 23: 75-80.

4. Amoakwa K, Martinson NA, Moulton LH, Barnes GL, Msandiwa R, et al. (2014) Risk factors for developing active tuberculosis after the treatment of latent tuberculosis in adults infected with human immunodeficiency virus. Open Forum Infect Dis 2: ofu120-ofu120.

5. Getahun H, Gunneberg C, Granich R, Nunn P (2010) HIV infectionassociated tuberculosis: the epidemiology and the response. Clin Infect Dis 50: S201-S207.

6. Owiti J (2009) Local knowledge of the link between tuberculosis and HIV-1/AIDS among the turkana of Lodwar township: Implications for tuberculosis and HIV-1/AIDS prevention. World Health Popul 10: 36-46.

7. Elhassan M, Hemeg HA, Elmekki MA, Turkistani KA, Abdul-Aziz AA (2016) The impact of mass gathering on the burden of multidrug resistant mycobacterium in Al-Madinah Al-Monawarah Region, Saudi Arabia. Infect Disord Drug Targets.

8. Dierberg KL, Chaisson RE (2013) Human immunodeficiency virusassociated tuberculosis: Update on prevention and treatment. Clin Chest Med 34: 217-228.

9. Ottenhoff THM, Kumararatne D, Casanova JL (1998) Novel human immunodeficiencies reveal the essential role of type-1 cytokines in immunity to intracellular bacteria. Immunol Today 19: 491-494.

10. Du Toit LC, Pillay V, Danckwerts MP (2006) Tuberculosis chemotherapy: Current drug delivery approaches. Respir Res 7: 118.

11. Pathak S, Wentzel-Larsen T, Asjö B (2010) Effects of in vitro HIV-1 infection on mycobacterial growth in peripheral blood monocyte-derived macrophages. Infect Immun 78: 4022-4032.

12. Ahmed N, Rani PS (2011) HIV-1/mycobacterium coinfection immunology: How does HIV-1 exacerbate tuberculosis. Infect Immun 79: 1407-1417.

13. Baba K, Sørnes S, Hoosen AA, Lekabe JM, Mpe MJ, et al. (2008) Evaluation of immune responses in HIV infected patients with pleural tuberculosis by the QuantiFERON TB-Gold interferon-gamma assay. BMC Infect Dis 8: 35 .

14. Bernard MB, Michele OS, Wesolowski LG, Berry B, Barbara, GW, et al. (2014) Laboratory testing for the diagnosis of HIV infection: updated recommendations. Centers for Disease Control and Prevention.

15. Saag MS (2014) Updates in HIV and AIDS: Part I, an issue of infectious disease clinics. Elsevier Health Sciences.

16. Sultan B, Benn P, Mahungu T, Young M, Mercey D, et al. (2013) Comparison of two interferon-gamma release assays (QuantiFERON-TB Gold In-Tube and T-SPOT.TB) in testing for latent tuberculosis infection among HIV-infected adults. Int J STD AIDS 24: 775-779.
17. Khawcharoenporn T, Apisarnthanarak A, Phetsuksiri B, Rudeeaneksin J, Srisungngam S (2014) Tuberculin skin test and QuantiFERON-TB gold in-tube test for latent tuberculosis in Thai HIV-infected adults. Respirology 20: 340-347.

18. Ramos JM, Robledano C, Masiá M, Belda S, Padilla S, et al. (2012) Contribution of interferon gamma release assays testing to the diagnosis of latent tuberculosis infection in HIV-infected patients: a comparison of QuantiFERON-TB Gold In Tube, T-SPOT.TB and tuberculin skin test. BMC Infect Dis 12: 169.

19. Ní Cheallaigh C, Cheallaigh CN, Fitzgerald I, Grace J, Singh GJ, et al. (2013) Interferon gamma release assays for the diagnosis of latent TB infection in HIV-infected individuals in a low TB burden country. PLoS One 8: e53330.

20. Pandie S, Peter JG, Kerbelker ZS, Meldau R, Theron G, et al. (2014) Diagnostic accuracy of quantitative PCR (Xpert MTB/RIF) for tuberculous pericarditis compared to adenosine deaminase and unstimulated interferon- $\gamma$ in a high burden setting: A prospective study. BMC Med 12: 101

21. Pooran A, Booth H, Miller RF, Scott G, Badri M, et al. (2010) Different screening strategies (single or dual) for the diagnosis of suspected latent tuberculosis: A cost effectiveness analysis. BMC Pulm Med 10: 7.

22. Liu C, Zhao Z, Fan J, Lyon CJ, Wu HJ, et al. (2017) Quantification of circulating Mycobacterium antigen peptides allows rapid diagnosis of active disease and treatment monitoring. Proc Natl Acad Sci U S A 114: 3969-3974.

23. McNerney R, Daley P (2011) Towards a point-of-care test for active tuberculosis: Obstacles and opportunities. Nat Rev Microbiol 9: 204-213.

24. Wang SF, Ou XC, Li Q, Zheng HW, Wang YF, et al. (2016) The Abbott RealTime MTB assay and the Cepheid GeneXpert assay show comparable performance for the detection of Mycobacterium in sputum specimens. Int J Infect Dis 45: 78-80.

25. Hoffmann H, Hofmann-Thiel S, Turaev L, Esenalieva A, Abdullaeva M, et al. (2012) Direct comparison of GeneXpert MTB/RIF (Cepheid) with probeTEC (Becton-Dickinson) and Taqman MTB (Roche) for detection of TB bacteria. Pneumologie 66: S01.

26. Landowski CP, Godfrey HP, Bentley-Hibbert SI, Liu X, Huang Z, et al. (2001) Combinatorial use of antibodies to secreted mycobacterial proteins in a host Immune system-independent test for tuberculosis. J Clin Microbiol 39: 2418-2424.

27. Armitige LY, Jagannath C, Wanger AR, Norris SJ (2000) Disruption of the genes encoding antigen 85A and antigen 85B of Mycobacterium H37Rv: Effect on growth in culture and in macrophages. Infect Immun 68: 767-778.

28. Harboe M, Wiker HG (1992) The $38-\mathrm{kDa}$ protein of mycobacterium tuberculosis: A review. J Infect Dis 166: 874-884.

29. Jung SB, Yang CS, Lee JS, Shin AR, Jung SS, et al. (2006) The Mycobacterial 38-Kilodalton glycolipoprotein antigen activates the mitogen-activated protein kinase pathway and release of proinflammatory cytokines through toll-like receptors 2 and 4 in human monocytes. Infect Immun 74: 2686-2696.

30. Steingart KR, Dendukuri N, Henry M, Schiller I, Nahid P, et al. (2009) Performance of purified antigens for serodiagnosis of pulmonary tuberculosis: A meta-analysis. Clin Vaccine Immunol 16: 260-276.

31. Uma Devi KR, Ramalingam B, Raja A (2003) Antibody response to Mycobacterium 30 and $16 \mathrm{kDa}$ antigens in pulmonary tuberculosis with human immunodeficiency virus coinfection. Diagn Microbiol Infect Dis 46: 205-209.

32. Raja A, Devi KRU, Ramalingam B, Brennan PJ (2004) Improved diagnosis of pulmonary tuberculosis by detection of free and immune complex-bound anti-30kDa antibodies. Diagn Microbiol Infect Dis 50: 253-259.

33. No authors listed (2017) Biology of HIV.

34. Litvinov J, Moen ST, Koh CY, Singh AK (2016) Centrifugal sedimentation immunoassays for multiplexed detection of enteric bacteria in ground water. Biomicrofluidics 10: 014103 
Citation: Litvinov J, Moen ST, Berry GJ, Loeffelholz M, Singh AK, et al. (2017) Centrifugal Microfluidic Platform for Rapid, Multiplexed Detection of TB and HIV Biomarkers in Whole Blood Samples. J Bioengineer \& Biomedical Sci 7: 230. doi:10.4172/2155-9538.1000230

Page 8 of 8

35. Koh CY, Schaff UY, Piccini ME, Stanker LH, Cheng LW, et al. (2015) Centrifugal microfluidic platform for ultrasensitive detection of botulinum toxin. Anal Chem 87: 922-928.

36. Moen ST, Hatcher CL, Singh AK (2016) A centrifugal microfluidic platform that separates whole blood samples into multiple removable fractions due to several discrete but continuous density gradient sections. PLoS One 11: e0153137.

37. Espitia C, Cervera I, González R, Mancilla RA (1989) 38-kD Mycobacterium antigen associated with infection. Its isolation and serologic evaluation. Clin Exp Immunol 77: 373-377.
38. Daniel TM, Debanne SM (1987) The serodiagnosis of tuberculosis and other mycobacterial diseases by enzyme-linked immunosorbent assay. Am Rev Respir Dis 135: 1137-1151.

39. Young DB, Perkins MD, Duncan K, Barry CE (2008) Confronting the scientific obstacles to global control of tuberculosis. J Clin Invest 118: 1255-1265.

40. Wares D (2009) Global tuberculosis control: The future prospects. Tuberculosis.pp: 874-893. 